\title{
Genomic organization and the tissue distribution of alternatively spliced isoforms of the mouse Spatial gene Magali Irla ${ }^{1}$, Denis Puthier ${ }^{1}$, Samuel Granjeaud ${ }^{1}$, Murielle Saade ${ }^{1}$, Geneviève Victorero ${ }^{1}$, Marie-Geneviève Mattei ${ }^{2}$ and Catherine Nguyen*1
}

\begin{abstract}
Address: ${ }^{1 E R M} 0206$ INSERM, Case 928, Parc Scientifique de Luminy, F-13288 Marseille Cedex 9, Université de la méditerranée, faculté de science de Luminy, Marseille, France and 2INSERM U491, faculté de medecine de la Timone, Marseille, France

Email: Magali Irla - irla@tagc.univ-mrs.fr; Denis Puthier - puthier@tagc.univ-mrs.fr; Samuel Granjeaud - granjeau@tagc.univ-mrs.fr; Murielle Saade - saade@tagc.univ-mrs.fr; Geneviève Victorero - victorero@tagc.univ-mrs.fr; Marie-Geneviève Mattei - Matteigenevieve.mattei@medecine.univ-mrs.fr; Catherine Nguyen* - nguyen@tagc.univ-mrs.fr

* Corresponding author
\end{abstract}

Published: 05 July 2004

BMC Genomics 2004, 5:4| doi:|0.|| 86/|47|-2|64-5-4|
Received: 30 April 2004

Accepted: 05 July 2004

This article is available from: http://www.biomedcentral.com/I47I-2|64/5/4I

(C) 2004 Irla et al; licensee BioMed Central Ltd. This is an Open Access article: verbatim copying and redistribution of this article are permitted in all media for any purpose, provided this notice is preserved along with the article's original URL.

\begin{abstract}
Background: The stromal component of the thymic microenvironment is critical for $T$ lymphocyte generation. Thymocyte differentiation involves a cascade of coordinated stromal genes controlling thymocyte survival, lineage commitment and selection. The "Stromal Protein Associated with Thymii And Lymph-node" (Spatial) gene encodes a putative transcription factor which may be involved in T-cell development. In the testis, the Spatial gene is also expressed by round spermatids during spermatogenesis.
\end{abstract}

Results: The Spatial gene maps to the B3-B4 region of murine chromosome 10 corresponding to the human syntenic region I0q22.I. The mouse Spatial genomic DNA is organised into 10 exons and is alternatively spliced to generate two short isoforms (Spatial- $\alpha$ and $-\gamma$ ) and two other long isoforms (Spatial- $\delta$ and $-\varepsilon$ ) comprising 5 additional exons on the 3 ' site. Here, we report the cloning of a new short isoform, Spatial- $\beta$, which differs from other isoforms by an additional alternative exon of 69 bases. This new exon encodes an interesting proline-rich signature that could confer to the $34 \mathrm{kDa}$ Spatial- $\beta$ protein a particular function. By quantitative TaqMan RT-PCR, we have shown that the short isoforms are highly expressed in the thymus while the long isoforms are highly expressed in the testis. We further examined the inter-species conservation of Spatial between several mammals and identified that the protein which is rich in proline and positive amino acids, is highly conserved.

Conclusions: The Spatial gene generates at least five alternative spliced variants: three short isoforms (Spatial- $\alpha,-\beta$ and $-\gamma$ ) highly expressed in the thymus and two long isoforms (Spatial- $\delta$ and $-\varepsilon$ ) highly expressed in the testis. These alternative spliced variants could have a tissue specific function.

\section{Background}

The immune system is composed of many interdependent cell types that collectively protect the body. The hemat- opoietic precursors leave the bone marrow and migrate into the thymus, primary site of $\mathrm{T}$ cells development, providing a unique microenvironment that efficiently 
generates functional $\mathrm{T}$ lymphocytes. This maturation requires the interaction of immature thymocytes with the thymic stroma. The lympho-epithelial interaction delivers signals necessary for survival, proliferation, differentiation and selection of developing thymocytes [1]. After a remarkable maturation process, mature $\mathrm{T}$ cells are then released into the bloodstream and migrate to secondary lymphoid organs, such as the spleen and lymph nodes.

Although the T cell differentiation process is well documented, little is known about the underlying stromal molecules involved in the lympho-epithelial interaction. In order to identify new stromal genes potentially involved in these mechanisms, we developed a systematic approach of gene expression profiling to evaluate, in comparison to the wild-type littermate, the gene expression of several thymus deficient mice showing a blockage at different stages of T cell development [2-4]. Among the identified stromal genes, we selected a gene, dependent on the three-dimensional organization of the thymus, named Spatial for "Stromal Protein Associated with Thymii And Lymph-node" [5]. RT-PCR analysis on 48 distinct mouse tissues showed that Spatial is highly expressed in the thymus and testis. In the testis, in situ hybridization experiments showed that Spatial expression is tightly regulated and restricted to step 2-10 in haploid round spermatids during spermiogenesis [6].

Here, we describe the genomic organization of the Spatial gene and subsequently identify a new alternatively spliced isoform expressed in the thymus. In addition, we precisely evaluate the tissue distribution of the alternative spliced variants of Spatial gene by quantitative TaqMan RT-PCR.

\section{Results and discussion Chromosomal localization}

We determined the chromosomal localization of Spatial gene by fluorescence in situ hybridization using a $40 \mathrm{~kb}$ cosmid isolated from the rzpd genomic library. $98 \%$ of 30 analysed metaphase cells showed specific fluorescent spots on the B3-B4 region of murine chromosome 10 (Fig. 1A). This single signal strongly suggests that Spatial does not belong to a gene family. This region contains the Sim 1 [7], Zfa [8], Hsf2 [9] and Edar [10] genes in the B3 band and Eif4ebp2 [11], Sgpl1 [12], Ddx21 [13] and Gp49b [14] genes in the B4 band (Fig. 1B). Furthermore, the human synthenic B3-B4 region is divided into two regions located on chromosome 6 and 10 where SIM1 and HSF2 genes are located on chromosome 6 and the SGPL1, DDX21 and EIF4ebp2 genes were mapped on chromosome 10. This observation suggests that these genes are respectively located above and below the mouse translocation points $\mathrm{T}(2 ; 10)$ and $\mathrm{T}(10 ; 18)$. In parallel, by BLAST analysis, we identified a chromosome 10q22.1 human contig which displays similarities to Spatial gene (Genbank Accession
No NT_008583) where no pathologies were described in this region until now. All together, these data show that Spatial is located on the mouse chromosome 10-B4 band between Ddx21 and Eif4ebp2 (Fig. 1C).

\section{Identification of a new alternative spliced variant of Spatial}

In order to study the stromal molecular mechanisms involved in T cell development, we isolated new genes, by quantitative differential screening using array technology, between wild-type and several knock-out mice models displaying a stromal disorganization. We screened from an adult mouse thymus library (ㅆo three Spatial cDNA clones: MTA.H09.096, MTA.C03.094 and MTA.F04.072 (GenBank Accession No. W91576, W91584, AY243458 respectively). In addition, by screening a 15 days embryonic thymus mouse library (ㅆouse Fetal Thymus, MFT, library accessible in the RZPD resource center), another Spatial cDNA clone was isolated: MFT.G17.012 (GenBank Accession No. AY243459).

The sequencing of these clones showed that MTA.C03.094 is similar to MTA.F04.072 while MTA.H09.096 and MTA.F04.072 differ by a 102 bases additional exon, corresponding to two adult variants already described in the thymus (GenBank Accession No. AF257502 and AF257503) [5]. In addition, sequence analysis of the MFT.G17.012 showed that it contains an additional exon of 69 bases. We confirmed the presence of this new exon by performing RT-PCR analysis on total RNA extract from adult mouse thymus, using specific primers for this new additional exon (Fig. 2A). Thereafter, we cloned and fully sequenced this third isoform reporting the expression of this new Spatial splicing variant in the thymus (GenBank Accession No. AY243457). According to the size of alternative spliced variants, the longest and the shortest isoforms were respectively named Spatial- $\alpha$ (1035 bp) and Spatial- $\gamma$ (933 bp) and the third new mid-sized isoform Spatial- $\beta$ (1002 bp) (Fig. 2A). In addition, we already described two other isoforms in the testis differing by the same 102 bases alternative exon mentioned above: Spatial- $\varepsilon$ (1454 bp) for the longest (GenBank Accession No. AF521592) and Spatial- $\delta$ (1353 bp) for the shortest (GenBank Accession No. AF521591) [6]. In order to study the protein product of Spatial, we have developped a polyclonal antibody to be able to recognize all isoforms. As shown in figure $2 \mathrm{~B}$, this antibody reacts with the three protein products of thymic isoforms on the nuclear extract. The apparent molecular masses of the upper and the lowest bands correspond to Spatial- $\alpha$ and Spatial- $\gamma$ at 38 and $32 \mathrm{kDa}$ respectively [5]. In the cytosolic fraction, we can detect Spatial- $\alpha$ which is probably not yet translocated into the nucleus. On the basis of the size of Spatial isoforms, we have deduced that the third band at $34 \mathrm{kDa}$ probably corresponds to the newly described Spatial- $\beta$ 


\section{B}
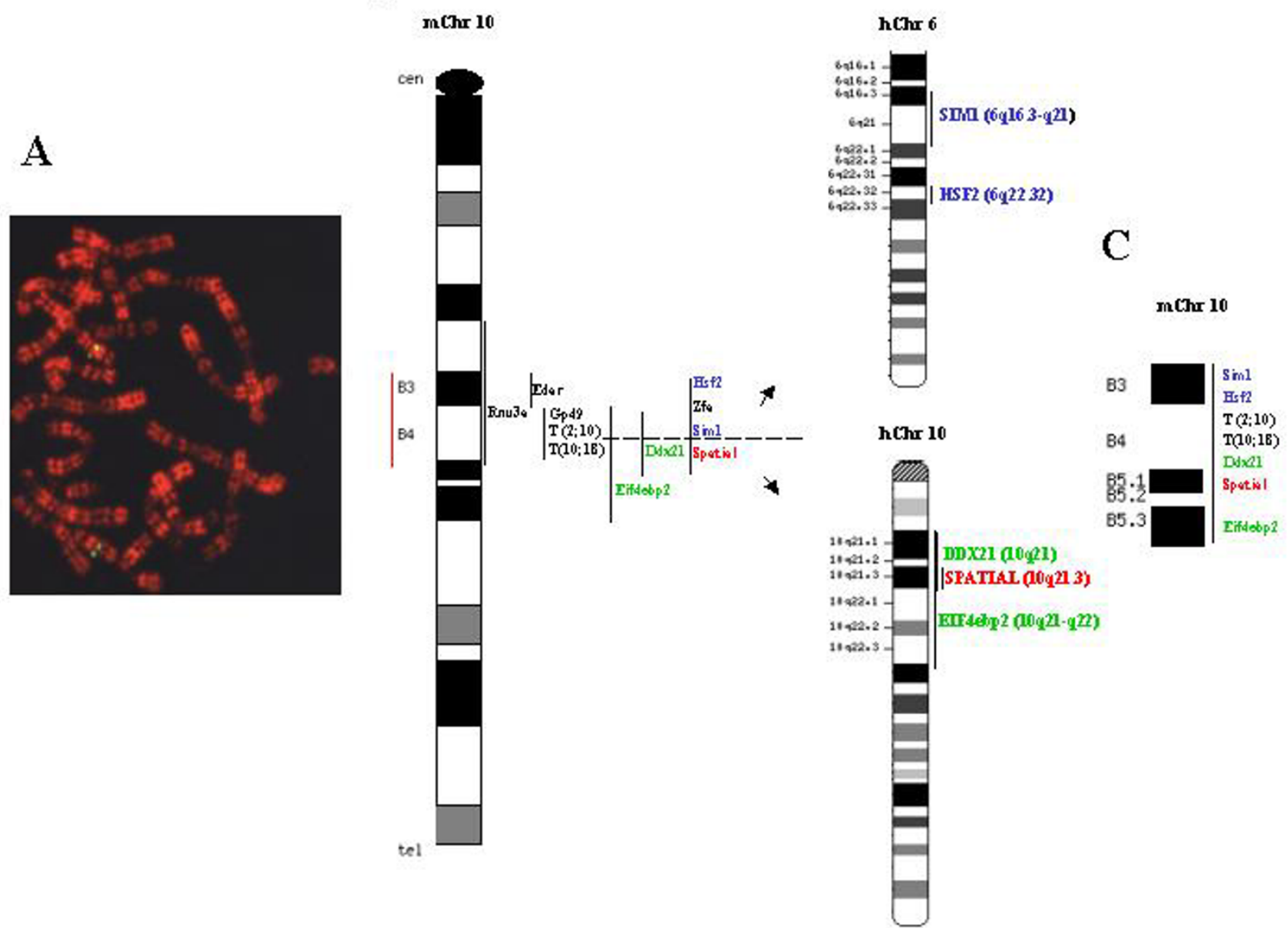

Figure I

Chromosomal localization. (A) Localization of the Spatial probe on WMP murine metaphase: R-banded chromosomes are red-stained with propidium iodide. The FITC fluorescent signals (green), corresponding to Spatial gene, are located on chromosome 10 and belong to the robertsonian translocation $\mathrm{Rb}(10$; I7). (B) On the left, the map of mouse chromosome 10 zooming on B3-B4 bands where are localized 2 translocation points, and on the right, 2 human syntenic regions located on Ch6 and $\mathrm{Ch}$ I0. (C) The repartition of genes within B3 to B5.3 bands on mouse chromosome 10.

suggesting that this isoform would generate a protein in the thymus.

\section{Organization of Spatial alternative spliced variants}

We determined by analyzing the mouse genomic contig (Mus musculus, Genbank Accession No. NT_039495) that Spatial is composed of 10 exons (Fig. 3A). Four exons of Spatial are present in Spatial- $\alpha,-\beta,-\gamma$ isoforms (exons 2, 3, 4 and 5) and 9 exons in Spatial- $\delta,-\varepsilon$ isoforms (exons 1, 3, 4, 5, 6, 7, 8, 9 and 10) (Fig. 3B). Spatial- $\alpha$ and Spatial- $\varepsilon$ contain an alternatively spliced internal region of 102 bases located in exon 4 and the new described Spatial- $\beta$ contains an alternatively spliced internal region of 69 bases in exon 5. The exon organization of Spatial- $\delta$ and $-\varepsilon$ shows that 5 exons are added at the 3 ' end compared to Spatial $-\alpha,-\beta,-\gamma$. In addition, the start and the stop codons are respectively localized in exon 2 and exon 5 for Spatial$\alpha,-\beta,-\gamma$ while they are localized in exon 1 and exon 10 for Spatial $-\delta,-\varepsilon$. We classified Spatial $-\alpha,-\beta,-\gamma$ as short isoforms and Spatial $-\delta,-\varepsilon$ as long isoforms. The exon length and the exact position of the start and the stop of different Spatial isoforms were determined by detailed analysis of mouse chromosome 10 (Table 1A,1B) [15]. Furthermore, short isoforms contain in the 3' end of exon 5 a nuclear localization signal (NLS) allowing the transport of the protein from the cytosol to the nucleus. This observation strongly 


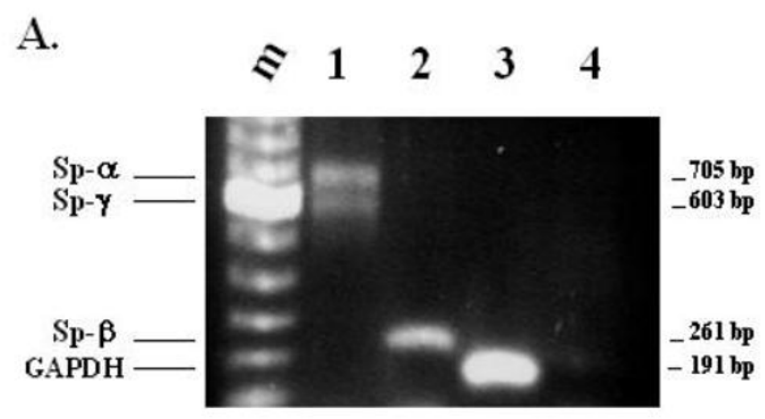

B.

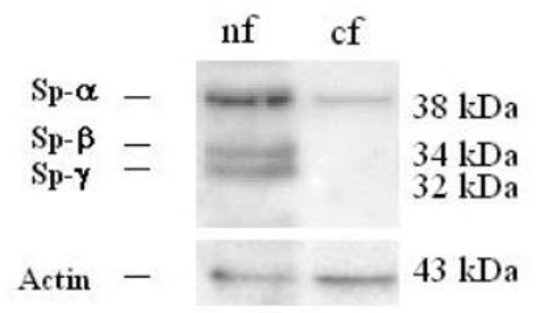

\section{Figure 2}

Study of Spatial- $\beta$ expression in the thymus. (A) Expression of Spatial- $\beta$ mRNA in the mouse thymus by RTPCR; the amplicons were the short Spatial isoforms: Spatial$\alpha,-\beta,-\gamma$ and the housekeeping gene GAPDH. The size of the amplicons are indicated. $\mathrm{m}, 100$ bp DNA marker; lane I, positive control, Spatial- $\alpha$, $-\gamma$; lane 2, Spatial- $\beta$; lane 3, GAPDH and lane 4, negative control. For the amplification of Spatial$\beta$, we used forward primer specific to the additional 69-bases while the reverse primer was specific to the exon 5 . (B) Analysis of Spatial- $\beta$ protein expression in the thymus; in the nuclear fraction (nf), bands at 38, 34 and $32 \mathrm{kDa}$ are detected corresponding to Spatial- $\alpha$, Spatial- $\beta$ and Spatial- $\gamma$ respectively. In the cytosolic fraction (cf), only one band at $38 \mathrm{kDa}$ is detected which corresponds to Spatial- $\alpha$ that could be under nuclear translocation process.

suggests that long and short isoforms could have different subcellular localizations which potentially leads to different functions.

\section{Tissue distribution of mouse Spatial isoforms}

Previous RT-PCR analysis on a large panel of mouse tissues showed that Spatial is highly expressed in the thymus and testis, but also to a lesser extent in brain cortex, cere- bellum and hippocampus [6]. In order to precisely decipher the tissue distribution of short and long Spatial isoforms, quantitative TaqMan RT-PCR was performed on the thymus, testis as well as the kidney as a negative control. The expression of Spatial isoforms in different adult tissues was measured relatively to the expression of the housekeeping 18S-rRNA gene.

This analysis shows a residual expression of 1.36 10-4 RQ value in the kidney for the two isoform types confirming a null expression, while short and long Spatial isoforms were differentially expressed in the thymus and the testis. Short isoforms are highly expressed in the thymus whereas long isoforms are highly expressed in the testis. Short isoforms are expressed in the thymus 85 -fold higher than the testis and an expression of 1.18 10-2 RQ value is observed in testis signing a basal expression (Fig. 4A). Long isoforms are expressed in the testis 25 -fold higher than the thymus and in this case the basal expression in the thymus is 3.9 10-2 RQ value (Fig. 4B).

This study reveals a mirror image of short and long isoforms expression in these organs. Actually, the basal expression detected by RT-PCR experiments which is very sensitive and known to amplifiy very low expression in classical conditions ( 30 cycles) can lead to an over estimation of the expression level analysis. Indeed, in the thymus only the short isoforms are translated and give rise to three corresponding proteins (see above). In addition, previous analyses on thymus sections have shown that Spatial gene is expressed by subcapsular stromal cells which are resident cells known to be involved in thymocytes development [16]. In testis, the Spatial gene is expressed in round spermatids which are migrating cells representing a cell stage prior to spermatozoa maturation [17]. In conclusion, short isoforms are highly expressed in the thymus and at a basal-rate in testis whereas long isoforms are highly expressed in the testis with a basal-rate in thymus. Major isoforms type are expressed in specific cell types suggesting a tissue specific function.

\section{Comparison of the mouse Spatial ortholog protein sequences}

We further examined the inter-species homologies by performing a BLAST search of the Expressed Sequence Tag (EST) database with Spatial mouse cDNA and identified several mammalian ESTs of pig (Sus scrofa, GenBank Accession No. BM484264) and bovine (Bos taurus, GenBank Accession No. BF077282) in addition to rat (GenBank Accession No. XM_228291) and human (GenBank Accession No. AK057382) [18,19]. The analysis of the rat EST showed that it corresponds to the mouse Spatial- $\varepsilon$ isoform. In addition, bioinformatic studies of the rat contig (Rattus norvegicus, Genbank Accession No NW_043448) showed that the corresponding EST, in 
A

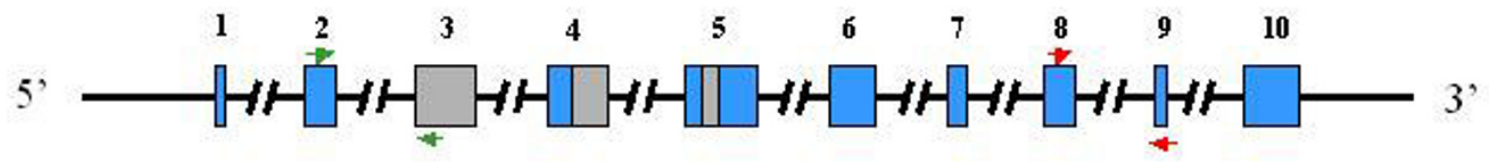

B

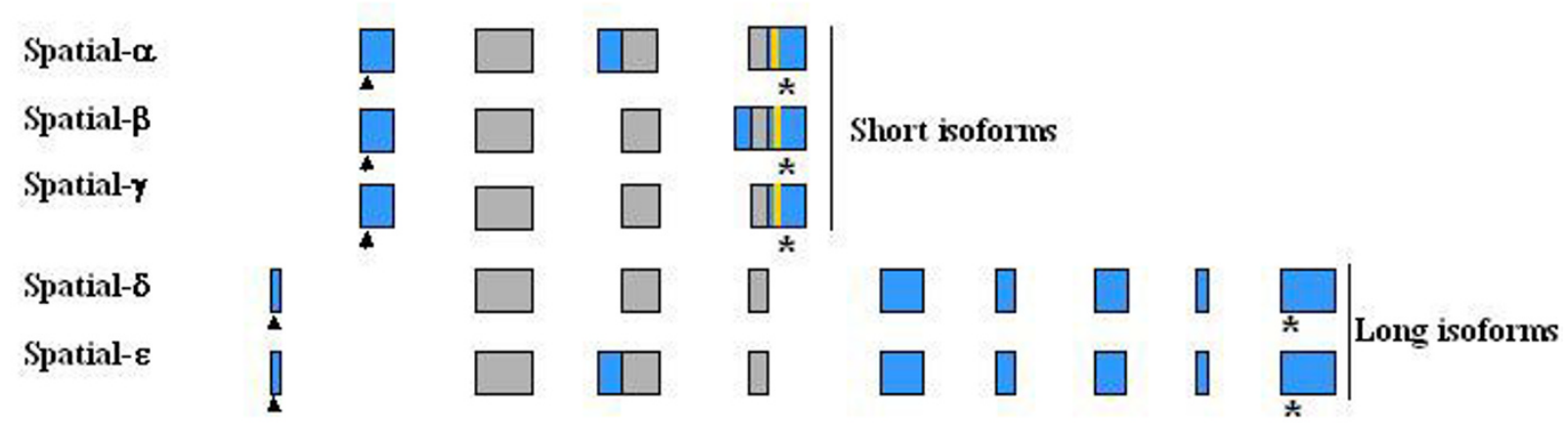

\begin{tabular}{|lcl|}
\hline * Start codon & $\square \quad$ Alternative exons \\
$*$ Stop codon & $\square \quad$ Exons common to all isoforms \\
$*$ Primers of long isoforms & $-/-$ Intronic regions \\
$*$ Primers of short isoforms & $\quad$ Nuclear localixation signal (NLS) \\
\hline
\end{tabular}

\section{Figure 3}

Genomic organization and alternative splicing pattern of Spatial gene in the mouse. (A) The mouse genomic sequence corresponding to the Spatial gene constituted of 10 exons. Alternative spliced exons are represented by blue boxes and common exons of the different Spatial isoforms are represented by gray boxes. Green and red arrows correspond to the designed primers specific for the Spatial short and long isoforms respectively used for the quantitative TaqMan RT-PCR experiment. (B) mRNA organization of Spatial isoforms: the Spatial short mRNA isoforms (Spatial- $\alpha,-\beta,-\gamma$ ) differ by a 102 bp additional exon for Spatial- $\alpha$ and 69 bp for the newly described Spatial- $\beta$ comparing to the shortest Spatial- $\gamma$ isoform. The NLS encoding sequence is represented by a yellow box, specific for short isoforms. The Spatial- $\delta$ isoform differs from Spatial- $\varepsilon$ isoform by a 102 bp additional exon. The predicted start codon indicated by $(\Delta)$ and the stop codon indicated by $(*)$ are localised in exon 2 and exon 5 for short isoforms and in exon I and exon 10 for long isoforms, respectively. Long and short isoforms differ by the addition of 5 exons in the 5 'end of long isoforms.

comparison to the mouse Spatial- $\varepsilon$ isoform, contains an additional exon in the 5 ' end separated from the second exon by an intron of about $8 \mathrm{~kb}$. Therefore, we performed an RT-PCR analysis with primers specific for the first predicted exon in the rat and deduced that this exon does not exist (data not shown). This result indicates that the Spatial- $\varepsilon$ mRNA contains 9 exons in rat as in mouse, while it is composed of 11 exons in human. The alignment of the deduced amino acid sequences is shown in figure 5 [see
Additional file 1]. As a reference, we have chosen the mouse Spatial- $\alpha$ protein, that shows $90 \%$ identity with other mouse Spatial isoforms and 55\% of inter-species homology. However, we did not find any EST from widely sequenced non-mammalian eukaryotes such as Drosophila melanogaster, Caenorhabditis elegans and Saccharomyces cerevisae. 
Table I: Exon-intron organization of Spatial gene in the mouse chromosome 10. (A) The exact size as the position of the start and the end of each exon are precisely calculated for different Spatial isoforms. The exon $\mathbf{4}$ contains two alternatively spliced internal regions $(4 \mathrm{a}, \mathrm{b})$ while the exon 5 contains three alternatively spliced internal regions $(5 \mathrm{a}, \mathrm{b}, \mathrm{c})$. (B) The exact position of the start, the stop and the polyA tail is calculated for short and long isoforms. Feature positions in bp are calculated relatively to position 63050000 of the mouse chromosome 10 (Ensembl build 32). Introns can not be determined because the genomic sequence contains stretches of nucleotides.

\section{A}

\begin{tabular}{|c|c|c|c|c|c|c|c|c|}
\hline \multirow[b]{2}{*}{ Exon } & \multirow[b]{2}{*}{ Start } & \multirow[b]{2}{*}{ End } & \multirow[b]{2}{*}{ Length } & \multicolumn{3}{|c|}{ Short isoforms } & \multicolumn{2}{|c|}{ Long isoforms } \\
\hline & & & & Spatial- $\alpha$ & Spatial- $\beta$ & Spatial- $\gamma$ & Spatial- $\delta$ & Spatial- $\varepsilon$ \\
\hline 1 & 3873 & 4027 & 155 & & & & $3873 \ldots 4027$ & $3873 \ldots .4027$ \\
\hline 2 & 4834 & 4975 & 142 & $4834 \ldots 4975$ & $4834 \ldots 4975$ & $4834 \ldots 4975$ & & \\
\hline 3 & 5303 & 5550 & 248 & $5303 \ldots 5550$ & $5303 \ldots 5550$ & $5303 \ldots 5550$ & $5303 \ldots 5550$ & $5303 \ldots 5550$ \\
\hline $4 a b$ & 8090 & 8350 & 261 & $8090 \ldots 8350$ & & & & $8090 \ldots 8350$ \\
\hline $4 \mathrm{~b}$ & 8192 & 8350 & 159 & & $8192 \ldots 8350$ & $8192 \ldots 8350$ & $8192 \ldots 8350$ & \\
\hline $5 \mathrm{abc}$ & 9093 & 9543 & 451 & & $9093 \ldots 9543$ & & & \\
\hline $5 \mathrm{bc}$ & 9160 & 9543 & 384 & $9160 \ldots 9543$ & & $9160 \ldots 9543$ & & \\
\hline $5 \mathrm{~b}$ & 9160 & 9239 & 80 & & & & $9160 \ldots 9239$ & $9160 \ldots 9239$ \\
\hline 6 & 12958 & 13149 & 192 & & & & $|2958 \ldots| 3 \mid 49$ & $12958 \ldots 13149$ \\
\hline 7 & 14960 & $|504|$ & 82 & & & & $|4960 \ldots| 504 \mid$ & $|4960 \ldots| 504 \mid$ \\
\hline 8 & 15696 & 15837 & 142 & & & & $\mid 5696 \ldots 15837$ & $|5696 \ldots| 5837$ \\
\hline 9 & 17083 & 17135 & 53 & & & & $17083 \ldots .17 \mid 35$ & $17083 \ldots 17 \mid 35$ \\
\hline 10 & 18002 & 18242 & 241 & & & & $|8002 \ldots| 8242$ & $|8002 \ldots| 8242$ \\
\hline
\end{tabular}

B

\begin{tabular}{cccc}
\hline & Start & Stop & PolyA Signal \\
\hline $\begin{array}{c}\text { Short } \\
\text { isoforms } \\
\begin{array}{c}\text { Long } \\
\text { isoforms }\end{array}\end{array}$ & 4917 & 9285 & 9499 \\
\hline
\end{tabular}

Bioinformatic analyses have predicted that the molecular weights of Spatial- $\alpha,-\beta$ and $-\gamma$ are $25.8,24.6$ and $22.2 \mathrm{kDa}$ respectively and present an isoelectric point of 10 . The apparent mobility of the in vivo proteins $(38,34$ and 32 $\mathrm{kDa}$ ) is greater than the predicted mass based on the cDNA sequence (Fig 2B), this could be explained by a post-translational modifications of these proteins. In addition short isoforms where the NLS sequence is conserved, are detected in the nuclear fraction of the thymus and present proline-rich domains (10\%) as there are two other positive amino acid rich domains (arginine, lysine, histidine) which seem to exhibit homology with zinc-finger proteins known to be involved in protein-DNA interaction [20], but the $\mathrm{C} 2 \mathrm{H} 2$ consensus motif is not conserved in Spatial proteins. In addition, the 23 amino acid alternative exon (residues 190-212), only found in Spatial- $\beta$, presents an interesting proline-rich signature (residues 196-208) that could confer to Spatial- $\beta$ a particular function. Moreover, these short isoforms possess a secondary structure with $72 \%$ of random coil, suggesting an unstable structure. So, these nuclear proteins may have to interact with DNA and other cofactors in order to stabilise their conformations. Concerning long isoforms, Spatial- $\delta$ and $-\varepsilon$ are encoded with a 40.2 and $43.8 \mathrm{kDa}$ prediction molecular mass and present an isoelectric point of 6.5. In contrast to short isoforms, they lost the NLS sequence but gained an additional rich leucine sequence $(15.5 \%)$ in the 3 ' end, with a high percentage of alpha-helix (44.5\%) suggesting a more stable structure.

Taking in consideration all these data, Spatial is a relatively well conserved protein in mammals. Long isoforms observed in human, mouse and rat display alpha-helix in the C-terminal region suggesting a stable structure of the protein. Short isoforms lack any similarity to other known domains apart the putative zinc-finger homology. However, conserving the NLS sequence, short isoforms encode nuclear factors which could play a role in transcriptional regulation cell process. Interestingly, we describe here a new short isoform Spatial- $\beta$, which has an additional 
A.

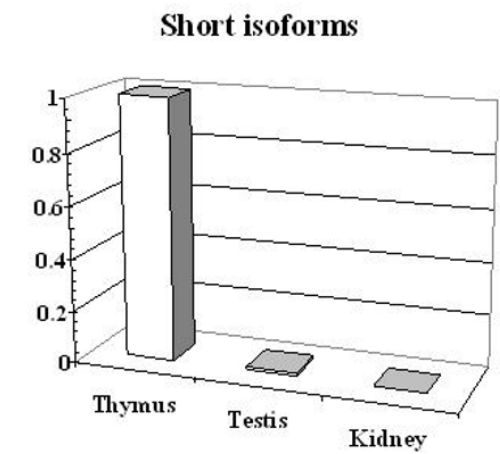

B.

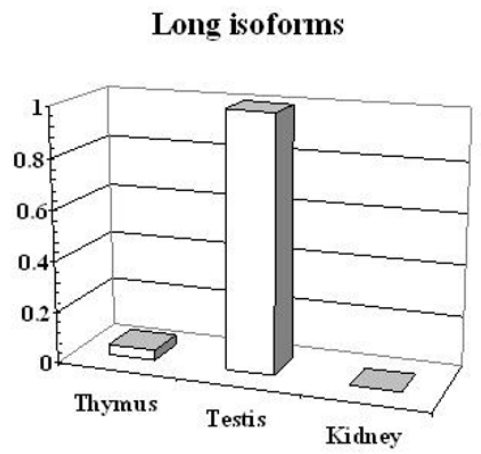

\section{Figure 4}

Expression of short and long Spatial mRNAs in mouse adult tissues by quantitative TaqMan RT-PCR. In each tissue, the expression levels of cDNA were normalised to the expression level of the housekeeping gene I8SrRNA. (A) The ratios of short Spatial mRNAs/I8S-rRNA from each tissue were standardised to short Spatial isoforms expression in the thymus which was taken as I. Range of standard deviation: thymus (0.849-I.152); testis (0.0090.014); kidney (I.I 1 $\left.0^{-4}-1.4 \quad 10^{-4}\right)$ (B) The ratios of long Spatial mRNAs/ I8S-rRNA from each tissue were standardised to long Spatial isoforms expression in the testis which was taken as I. The tissues examined were: thymus, testis and the kidney chosen as negative control. Range of standard deviation: thymus (0.030-0.050); testis (0.839-I.19I); kidney (1.2 10-4 I. $4\left(0^{-4}\right)$;

proline domain that could confer a specific function to this isoform.

\section{Conclusions}

We report the genomic characterization of the Spatial gene, which presents three short and two long splice variants. Here, a new Spatial isoform is characterized: it contains a sequence encoding for NLS protein signal and an internal splice site producing a 69 bases exon 5 encoding a proline-rich domain. Short isoforms are highly expressed in the thymus by stromal cells which are involved in T cell development. Long isoforms are highly expressed by round spermatids in testis, and appear to be involved in a specific stage of spermatozoa differentiation. This unique gene, localized in $\mathrm{B} 4$ band of mouse chromosome 10, is well conserved in mammals and displays 5 different messengers generated by alternative splicing which is one of the main process for differential expression in mammals [21-23]. Future work is now required to understand Spatial specific tissues function and link alternatively spliced isoforms to specific promoter regulatory elements.

\section{Methods \\ Animals}

Mice C57BL/ 6 were maintained under specific-pathogenfree conditions and used between 4 to 8 weeks of age. All experimental and surgical procedures involving animals were approved by the veterinary office of the Ministry of agriculture, France.

\section{RT-PCR}

Total RNA was purified using TRIzol reagent (Gibco-BRL, Life Technologies). Single-strand cDNA was synthesized by reverse transcription on $0.3-5 \mu \mathrm{g}$ of total RNA using oligo(dT) ${ }_{25}$ and SuperScript II (Gibco-BRL) in a final volume of $20 \mu \mathrm{l}$. PCR reaction was performed in a PTC 200 Peltier Thermal Cycler (MJ research) using $2 \mu \mathrm{l}$ of the RT reaction product in a final volume of $50 \mu \mathrm{l}$, using the following conditions: $94^{\circ} \mathrm{C}$ for $3 \mathrm{~min}$ ( 1 cycle), 30 cycles of $94^{\circ} \mathrm{C}$ for $30 \mathrm{~s}, 62^{\circ} \mathrm{C}$ for $40 \mathrm{~s}, 72^{\circ} \mathrm{C}$ for $1 \mathrm{~min}$, and $72^{\circ} \mathrm{C}$ for $10 \mathrm{~min}$ ( $1 \mathrm{cycle})$. Of the amplification product, $10 \mu \mathrm{l}$ were resolved on a $1 \%$ agarose gel. The sequence primers used to detect specifically Spatial- $\beta$ are: forward primer: 5'-CTGAAGACAGGGAGGACA-3' and reverse primer 5'CGCTGTCACCTTCGAGGTTA- 3 ' while Spatial- $\alpha,-\gamma$ were amplified with forward primer: 5'-AGTCCAAAGGCAGAGCCCCA-3' reverse primer 5'-CGCTGTCACCTTCGAGGTTA-3' and the housekeeping gene GAPDH with forward primer: 5'-AACGACCCCTTCATTGAC-3' and reverse primer 5'-TCCACGACATACTC AGCAC-3'

\section{Protein preparation and immunoblot analysis}

To analyze the protein expression of Spatial- $\beta$, thymus from 4 weeks old mice was pounded. Nuclear and cytosolic proteins were separated by using the Nuclear Protein Extraction Kit (Panomics). Protein concentrations were measured using the Pierce BCA protein assay. For western-blot, total nuclear and cytosolic proteins were electrophoresed on SDS-polyacrylamide gel already prepared (Invitrogen) and transferred to Nitrocellulose membranes (BioRad) following incubation with the purified Spatial polyclonal antibody $(1: 2500)$. This antibody was 
produced by immunizing two rabbits against the mouse recombinant $6 \times$ His Spatial- $\alpha$ protein isoform and further purified on a protein $\mathrm{G}$ column (Eurogentec). Rabbit polyclonal anti-actin was used as a control charge (1:600; Santa cruz biotechnology). Proteins were visualized using horseradish peroxidase-conjugated secondary antibody (1:1000; Amersham Pharmacia Biotech) and the enhanced chemiluminescence (ECL) detection system (Pierce).

\section{Quantitative TaqMan RT-PCR}

Quantitative RT-PCR was performed on the thymus, testis and kidney chosen as a negative control to evaluate the distribution of the short and long Spatial isoforms by using the ABI PRISM 7000 Sequence Detection System. Random hexamers and the TaqMan reverse transcription reagents from the RT reaction mix (Applied Biosystems) were used to reverse transcribe total RNA. After, the PCR step was performed with TaqMan universal PCR master Mix and assays-on-demand gene expression probes (Applied Biosystems). Primers and the TaqMan probe used to detect specifically short isoforms were: forward primer: 5'-TTGGAACCAGCCCCTGTTT-3', reverse primer 5'-GTTCTCCGGCTTCGTCTCT-3' and FAM 5'-CCTTTGGACTAGTCACCTCAT-3' NFQ, respectively. Primers and the TaqMan probe used to detect specifically long isoforms were: forward primer: 5'-GCTTCAAGAGCCTCAAGAGACA-3', reverse primer 5'-GGTGGTGACCTAGTCTT CTTCAG-3' and FAM 5'-ACTGTAGGCTGCCTCTTG-3' NFQ, respectively. The 18S-rRNA was amplified from all samples on each plate as a housekeeping gene to normalize expression between different samples and to monitor assay reproducibility. A non-template control was included for each target analysed. Relative quantification of all targets was calculated by using the comparative cycle threshold method [24].

\section{Fluorescence in situ hybridization}

Metaphase spreads were prepared from a WMP female mouse, in which all the autosomes except chromosome 19 were in the form of metacentric Robertsonian translocations [25] Concanavalin A-stimulated lymphocytes were cultured at $37^{\circ} \mathrm{C}$ for $72 \mathrm{~h}$ with 5-bromodeoxyuridine added for the final $6 \mathrm{~h}$ of culture $(60 \mu \mathrm{g} / \mathrm{ml}$ of medium $)$ to ensure a chromosomal R-banding of good quality. The Spatial clone was biotinylated by random priming with biotin-14-dUTP, as outlined by the Gibco-BRL protocol (Life Technologies). Hybridization to chromosome spreads was performed with standard protocol. The biotin-labelled DNA was mixed with hybridization solution at a final concentration of $10 \mu \mathrm{g} / \mathrm{ml}$ and used $80 \mathrm{ng}$ per slide. Before hybridization, the labelled probe was annealed with a 250 -fold excess amount of murine Cot-1 DNA (Gibco-BRL) (for 45 minutes at $37^{\circ} \mathrm{C}$ ) in order to compete the aspecific repetitive sequences. The hybrid- ized probe was detected by means of fluorescence isothiocyanate-conjugated avidin (Vector laboratories). Chromosomes were counterstained and R-banded with propidium iodide diluted in antifade solution $\mathrm{pH}$ 11.0.

\section{Sequence analysis}

For the chromosomal localization, the genomic cosmid was isolated from rzpd genomic library http:// www.rzpd.de. The human-mouse homology map was analysed with NCBI synteny database http:// www.ncbi.nlm.nih.gov/Homology/. The Spatial corresponding contig was downloaded from the Ensembl Genome Browser http://www.ensembl.org. BLAST searches were conducted using the BLAST server http:// www.ncbi.nlm.nih.gov/BLAST. The exact size and precise position of the start and the end of each exon for different Spatial isoforms are calculated using the AAT server http:/ /genome.cs.mtu.edu/aat/aat.html. The sequence translation, exon organization, the multiple alignment and protein signature sequences have been analysed with Biology workbench http://workbench.sdsc.edu/.

\section{Abbreviations}

NCBI: National Centre of Biotechnology Information. RTPCR: Reverse Transcription Polymerase Chain Reaction. BLAST: Basic Local Alignment Search Tool

\section{Authors' contributions}

MI contributed to the conception, design, and coordination; conducted the expression experiments, cloning, sequencing analysis, and. wrote parts of the manuscript.

DP participated in helpful discussion concerning the conception, and coordination of this study.

SG participated in helpful discussion concerning the revision and the sequence analysis.

FL participated to the analysis of mouse ortholog of Spatial gene.

GV participated to technical advises and maintenance of the laboratory.

MGM conducted the experiment of fluorescent in situ hybridization.

$\mathrm{CN}$ participated in the conception, designed, and coordination of the study and edited the manuscript.

All authors read and approved the final manuscript. 


\section{Additional material}

\section{Additional File 1}

Figure 5: Word: document, sequence comparison of Spatial orthologs with the mouse protein. Sequence comparison of Spatial proteins in different species: Sus scrofa, $S s$; Bos Taurus, $B t$; Homo sapiens, $H s$; Mus musculus, Mm and Rattus norvegicus, Rn. Residues conserved with the mouse protein are shown by $\left({ }^{*}\right)$, strongly conserved residues by (:) and weakly conserved residues by (.). Residues are colour coded: basic, DE, blue; acidic, KR, pink; polar, CGHNQSTY, green and hydrophobic, AFILMPVW, red. The start and the stop of translation for the different protein isoforms, are indicated by a red $\underline{M}$ and $\left({ }^{*}\right)$, respectively. A proline rich domain, specific of Spatial- $\beta$ isoform, is highlighted in gray. Two positive amino acid rich domains are underlined. A putative nuclear localization signal is indicated, NLS and highlighted in yellow.

Click here for file

[http://www.biomedcentral.com/content/supplementary/14712164-5-41-S1.doc]

\section{Acknowledgments}

We thanks Dr. Daniel Gautheret and Dr. Nadia Dahmane for their detailed reading of the manuscript and useful suggestions. This work was supported by Institut National de la Santé et de la Recherche Médicale (INSERM). Magali Irla is supported by a PhD fellowship from the Ministère de l'Enseignement Supérieur et de de la Recherche. Denis Puthier is supported by an ANRS post-doctoral fellowship. Murielle Saade is supported by a grant from the INSERM région Provence-Alpes-Côte d'Azur. TaqMan experiment were realised using the platform of Marseille-Nice genopole ${ }^{\circledR}$.

\section{References}

I. Kisielow P, von Boehmer $\mathrm{H}$ : Development and selection of $\mathbf{T}$ cells: facts and puzzles. Adv Immunol 1995, 58:87-209.

2. Nguyen C, Rocha D, Granjeaud S, Baldit M, Bernard K, Naquet P, Jordan BR: Differential gene expression in the murine thymus assayed by quantitative hybridization of arrayed cDNA clones. Genomics 1995, 29:207-216.

3. Carrier A, Nguyen C, Victorero G, Granjeaud S, Rocha D, Bernard K, Miazek A, Ferrier P, Malissen M, Naquet P, Malissen B, Jordan BR: Differential gene expression in CD3epsilon- and RAG I-deficient thymuses: definition of a set of genes potentially involved in thymocyte maturation. Immunogenetics 1999, 50:255-270.

4. Wurbel MA, Philippe JM, Nguyen C, Victorero G, Freeman T, Wooding P, Miazek A, Mattei MG, Malissen M, Jordan BR, Malissen B, Carrier $A$, Naquet $P$ : The chemokine TECK is expressed by thymic and intestinal epithelial cells and attracts double- and singlepositive thymocytes expressing the TECK receptor CCR9. Eur J Immunol 2000, 30:262-27I.

5. Flomerfelt FA, Kim MG, Schwartz RH: Spatial, a gene expressed in thymic stromal cells, depends on three-dimensional thymus organization for its expression. Genes Immun 2000, I:39I-40I.

6. Irla M, Puthier D, Le Goffic R, Victorero G, Freeman T, Naquet $P$, Samson M, Nguyen C: Spatial, a new nuclear factor tightly regulated during mouse spermatogenesis. Gene Expr Patterns 2003, 3: $135-138$.

7. Ema M, Morita M, Ikawa S, Tanaka M, Matsuda Y, Gotoh O, Saijoh Y, Fujii H, Hamada H, Kikuchi Y, Fujii-Kuriyama Y: Two new members of the murine Sim gene family are transcriptional repressors and show different expression patterns during mouse embryogenesis. Mol Cell Biol 1996, 16:5865-5875.

8. Ashworth A, Skene B, Swift S, Lovell-Badge R: Zfa is an expressed retroposon derived from an alternative transcript of the $\mathrm{Zfx}$ gene. Embo J 1990, 9:1529-1534.

9. Goodson ML, Park-Sarge OK, Sarge KD: Tissue-dependent expression of heat shock factor 2 isoforms with distinct transcriptional activities. Mol Cell Biol 1995, 15:5288-5293.
10. Koppinen P, Pispa J, Laurikkala J, Thesleff I, Mikkola ML: Signaling and subcellular localization of the TNF receptor Edar. Exp Cell Res 200I, 269:180-192.

II. Gingras AC, Raught B, Sonenberg N: elF4 initiation factors: effectors of mRNA recruitment to ribosomes and regulators of translation. Annu Rev Biochem 1999, 68:913-963.

12. Liepkalns VA, Myher J], Kuksis A, Leli U, Freysz N, Hauser G: Molecular species of glycerophospholipids and diacylglycerols of cultured SH-SY5Y human neuroblastoma cells. Biochem Cell Biol I993, 71:|4|-| 49.

13. Valdez BC, Yang H, Hong E, Sequitin AM: Genomic structure of newly identified paralogue of RNA helicase II/Gu: detection of pseudogenes and multiple alternatively spliced mRNAs. Gene 2002, 284:53-61.

14. Castells MC, Wu X, Arm JP, Austen KF, Katz HR: Cloning of the gp49B gene of the immunoglobulin superfamily and demonstration that one of its two products is an early-expressed mast cell surface protein originally described as gp49. J Biol Chem 1994, 269:8393-840I.

15. Huang X, Adams MD, Zhou H, Kerlavage AR: A tool for analyzing and annotating genomic sequences. Genomics 1997, 46:37-45.

16. Prockop S, Petrie HT: Cell migration and the anatomic control of thymocyte precursor differentiation. Semin Immunol 2000, 1 2:435-444.

17. Grootegoed JA, Siep M, Baarends WM: Molecular and cellular mechanisms in spermatogenesis. Baillieres Best Pract Res Clin Endocrinol Metab 2000, 14:33I-343.

18. Fahrenkrug SC, Smith TP, Freking BA, Cho J, White J, Vallet J, Wise T, Rohrer G, Pertea G, Sultana R, Quackenbush J, Keele JW: Porcine gene discovery by normalized cDNA-library sequencing and EST cluster assembly. Mamm Genome 2002, 13:475-478.

19. Smith TP, Grosse WM, Freking BA, Roberts AJ, Stone RT, Casas E, Wray JE, White J, Cho J, Fahrenkrug SC, Bennett GL, Heaton MP, Laegreid WW, Rohrer GA, Chitko-McKown CG, Pertea G, Holt I, Karamycheva S, Liang F, Quackenbush J, Keele JW: Sequence evaluation of four pooled-tissue normalized bovine CDNA libraries and construction of a gene index for cattle. Genome Res 200I, I I:626-630.

20. Hobohm U, Sander C: A sequence property approach to searching protein databases. J Mol Biol 1995, 25 I:390-399.

21. Xu Q, Modrek B, Lee C: Genome-wide detection of tissue-specific alternative splicing in the human transcriptome. Nucleic Acids Res 2002, 30:3754-3766.

22. Modrek B, Lee CJ: Alternative splicing in the human, mouse and rat genomes is associated with an increased frequency of exon creation and/or loss. Nat Genet 2003, 5:5.

23. Waterston RH, Lindblad-Toh K, Birney E, Rogers J, Abril JF, Agarwal P, Agarwala R, Ainscough R, Alexandersson M, An P, Antonarakis SE, Attwood J, Baertsch R, Bailey J, Barlow K, Beck S, Berry E, Birren B, Bloom T, Bork P, Botcherby M, Bray N, Brent MR, Brown DG, Brown SD, Bult C, Burton J, Butler J, Campbell RD, Carninci P, Cawley S, Chiaromonte F, Chinwalla AT, Church DM, Clamp M, Clee C, Collins FS, Cook LL, Copley RR, Coulson A, Couronne O, Cuff J, Curwen V, Cutts T, Daly M, David R, Davies J, Delehaunty KD, Deri J, Dermitzakis ET, Dewey C, Dickens NJ, Diekhans M, Dodge S, Dubchak I, Dunn DM, Eddy SR, Elnitski L, Emes RD, Eswara P. Eyras E, Felsenfeld A, Fewell GA, Flicek P, Foley K, Frankel WN, Fulton LA, Fulton RS, Furey TS, Gage D, Gibbs RA, Glusman G, Gnerre S, Goldman N, Goodstadt L, Grafham D, Graves TA, Green ED, Gregory S, Guigo R, Guyer M, Hardison RC, Haussler D, Hayashizaki Y, Hillier LW, Hinrichs A, Hlavina W, Holzer T, Hsu F, Hua A, Hubbard T, Hunt A, Jackson I, Jaffe DB, Johnson LS, Jones M, Jones TA, Joy A, Kamal M, Karlsson EK, Karolchik D, Kasprzyk A, Kawai J, Keibler E, Kells C, Kent WJ, Kirby A, Kolbe DL, Korf I, Kucherlapati RS, Kulbokas EJ, Kulp D, Landers T, Leger JP, Leonard S, Letunic I, Levine R, Li J, Li M, Lloyd C, Lucas S, Ma B, Maglott DR, Mardis ER, Matthews L, Mauceli E, Mayer JH, McCarthy M, McCombie WR, McLaren S, McLay K, McPherson JD, Meldrim J, Meredith B, Mesirov JP, Miller W, Miner TL, Mongin E, Montgomery KT, Morgan M, Mott R, Mullikin JC, Muzny DM, Nash WE, Nelson JO, Nhan MN, Nicol R, Ning Z, Nusbaum C, O'Connor MJ, Okazaki Y, Oliver K, Overton-Larty E, Pachter L, Parra G, Pepin KH, Peterson J, Pevzner P, Plumb R, Pohl CS, Poliakov A, Ponce TC, Ponting CP, Potter S, Quail M, Reymond A, Roe BA, Roskin KM, Rubin EM, Rust AG, Santos R, Sapojnikov V, Schultz B, Schultz J, Schwartz MS, Schwartz S, Scott C, Seaman S, Searle S, Sharpe T, Sheridan A, Shownkeen R, Sims S, Singer JB, Slater G, Smit A, Smith 
DR, Spencer B, Stabenau A, Stange-Thomann N, Sugnet C, Suyama M, Tesler G, Thompson J, Torrents D, Trevaskis E, Tromp J, Ucla C, Ureta-Vidal A, Vinson JP, Von Niederhausern AC, Wade CM, Wall M, Weber RJ, Weiss RB, Wendl MC, West AP, Wetterstrand K, Wheeler R, Whelan S, Wierzbowski J, Willey D, Williams S, Wilson RK, Winter E, Worley KC, Wyman D, Yang S, Yang SP, Zdobnov EM, Zody MC, Lander ES: Initial sequencing and comparative analysis of the mouse genome. Nature 2002, 420:520-562.

24. Livak KJ, Schmittgen TD: Analysis of relative gene expression data using real-time quantitative PCR and the 2(-Delta Delta C(T)) Method. Methods 200I, 25:402-408.

25. Bonhomme F, Guénet J-L: The wild house mouse and its relative. In "Genetic Variants and Strains of the Laboratory Mouse". 2nd edition. Edited by: Lyon MF and Searle AG. oxford, Oxford Univ. Press; 1989:. 649-662.

Publish with Biomed Central and every scientist can read your work free of charge

"BioMed Central will be the most significant development for disseminating the results of biomedical research in our lifetime. "

Sir Paul Nurse, Cancer Research UK

Your research papers will be:

- available free of charge to the entire biomedical community

- peer reviewed and published immediately upon acceptance

- cited in PubMed and archived on PubMed Central

- yours - you keep the copyright

Submit your manuscript here:

http://www.biomedcentral.com/info/publishing_adv.asp
BioMedcentral 